Published in final edited form as:

Nat Rev Microbiol. 2008 January ; 6(1): 17-27.

\title{
The biology and future prospects of antivirulence therapies
}

\author{
Lynette Cegelski ${ }^{*}$, Garland R. Marshall ${ }$, Gary R. Eldridge $§$, and Scott J. Hultgren ${ }^{\star}$ \\ ${ }^{*}$ Department of Molecular Microbiology, Washington University, Saint Louis, Missouri 63110, USA \\ $\ddagger$ Center for Computational Biology and Department of Biochemistry and Molecular Biophysics, Washington \\ University, Saint Louis, Missouri 63110, USA
}

§ Sequoia Sciences, Saint Louis, Missouri 63114, USA

\section{Abstract}

The emergence and increasing prevalence of bacterial strains that are resistant to available antibiotics demand the discovery of new therapeutic approaches. Targeting bacterial virulence is an alternative approach to antimicrobial therapy that offers promising opportunities to inhibit pathogenesis and its consequences without placing immediate life-or-death pressure on the target bacterium. Certain virulence factors have been shown to be potential targets for drug design and therapeutic intervention, whereas new insights are crucial for exploiting others. Targeting virulence represents a new paradigm to empower the clinician to prevent and treat infectious diseases.

Bacteria that are resistant to current antibiotics have wreaked havoc in the clinic and are a primary cause of death in the intensive-care units of our hospitals worldwide ${ }^{1,2}$. Currently, most infections are caused by important bacterial pathogens, such as Staphylococcus aureus, that are penicillin resistant, and up to 50\% are resistant to stronger drugs, such as meticillin ${ }^{3}$. Meticillin-resistant S. aureus (MRSA) infections have reached epidemic levels this autumn (2007) in some parts of the United States, and are spreading through many sports centres, schools and gymnasiums, affecting predominantly student athletes, but also younger schoolchildren, and have already caused deaths in a matter of weeks. Moreover, as most bacterial strains are becoming resistant to multiple antibiotics, including vancomycin (the current drug of choice for the treatment of MRSA), there is an urgent need for antibiotics that have new modes of action on therapeutic targets 4,5 .

Currently used antibiotics were derived by screening natural products and compound libraries against whole organisms, which identified compounds that have bac-teriostatic or bacteriocidal activity. Analogues of these parent drugs, which have improved potency, pharmacological properties and efficacy against resistant strains, have increased the number of antibiotics that are clinically available ${ }^{6}$. However, the commercialization of new classes of antibiotics over the past 20 years has not met expectations, and current pharmaceutical pipelines lack new, broad-spectrum antibiotics ${ }^{7-9}$. The antibiotics that are available today are primarily variations on a single theme - bacterial eradication based on different modes of action at the molecular

Correspondence to S.J.H. e-mail: hultgren@ borcim.wustl.edu.

Competing interest statement

The authors declare competing financial interests: see web version for details.

DATABASES

Entrez Genome Project: http://www.ncbi.nlm.nih.gov/entrez/query.fcgi?db=genomeprj

Bacillus anthracis | Chlamydia trachomatis | Clostridium botulinum | Escherichia coli | Haemophilus influenzae | Helicobacter pylori |

Pseudomonas aeruginosa | Shigella dysenteriae | Shigella flexneri | Staphylococcus aureus | Streptococcus pneumoniae | Vibrio cholerae | Vibrio fischeri | Yersinia pestis | Yersinia pseudotuberculosis

FURTHER INFORMATION

Scott J. Hultgren's homepage: http://hultgren.wustl.edu/public 
level. Some target cell-wall biosynthesis, whereas others inhibit protein synthesis or DNA replication. More recently, fatty-acid biosynthesis has been proposed as a viable bactericidal target. Lysine analogues have also been identified that target lysine riboswitches and inhibit bacterial growth ${ }^{10}$. Further study of such new targets is an important element in the development of new drugs. However, all these strategies target bacterial cellular processes that are crucial for microbial survival. In our current battle against infectious diseases, clinicians are limited to the use of antibiotics that stimulate bacterial evolution ${ }^{11,12}$. New tactics and weapons are needed to combat bacteria that are, owing to evolution and selection, moving targets.

Targeting bacterial virulence is an alternative approach to the development of new antimicrobials that can be used to disarm pathogens in the host ${ }^{13-15}$. The overall strategy is to inhibit specific mechanisms that promote infection and are essential to persistence in a pathogenic cascade (for example, binding, invasion, subversion of host defences and chemical signalling), and/or cause disease symptoms (for example, the secretion of toxins). Stripping microorganisms of their virulence properties without threatening their existence may offer a reduced selection pressure for drug-resistant mutations. Virulence-specific therapeutics would also avoid the undesirable dramatic alterations of the host microbiota that are associated with current antibiotics. Indeed, the microbial cells that comprise the microbiota of a healthy human outnumber human cells by tenfold ${ }^{16}$; they colonize distinct sites throughout the body and confer numerous advantages to the host, some of which are only beginning to be understood. The balance of bacterial populations in the gut, for example, influences energy harvest and caloric intake through complex interbacterial metabolic networks ${ }^{17}$. The microbiota is dynamic, and shifts in the balance of microorgan-isms that alter the sizes of different bacterial populations - for example, the use of traditional antibiotic therapy - can lead to the loss of symbiotic benefits and the proliferation of disease-causing opportunistic pathogens.

A commitment to develop therapeutics that target virulence requires a serious change in our perspective for treating infectious diseases. Some elements of virulence do seem to be fundamental for many pathogens, and drugs that target these elements should exhibit broaderspectrum activity. However, many antivirulence drugs could be designed to target specific pathogens and the virulence factors that are unique to their pathogenic cascades. In addition, virulence-gene expression is a function of time and space throughout infection, in which factors such as pili could function early to mediate adhesion, and others, such as toxin production and quorum sensing (QS), could operate later, and in a different niche, as bacteria replicate and respond to host defences. As the coordinated regulation of virulence-gene expression is dynamic and location specific in the host, it should be possible to identify and target vital genetic or molecular bottlenecks - that is, to target the Achilles' heel of a pathogen during infection ${ }^{18-20}$. Systems biology is engaged in mapping the genetic control networks and molecular correlates of pathogenesis (ideally, using parameters obtained from relevant in vivo models) to drive the discovery of these bottlenecks and identify new drug targets.

Vaccination and other immunomodulatory strategies are additional crucial avenues that are being pursued to combat infectious disease and antibiotic resistance, both in immunocompetent and immunologically compromised hosts. The complex relationship between host immunity and microbial pathogenesis, the balance between protective immunity and immunopathology and strategies to exploit the many networks that are involved in antimicrobial strategies have been extensively reviewed ${ }^{21-24}$ and will not be discussed in detail here. In this Review, we highlight the diversity of the bacterial virulence mechanisms and consider their consequences in infectious disease. We review recent efforts towards antivirulence-based drug discovery in the framework of marketable drugs, and discuss the challenges that remain and factors that are crucial to developing the antivirulence therapeutic approach. 


\section{Microbial attachment and invasion}

The physical interaction between the pathogen and the host is crucial to the pathogenesis of virtually every bacterial disease. Specific proteins called adhesins mediate the adhesive interactions between the pathogen and a cell-surface ligand on the host cell that is required for host colonization. The ability to impair bacterial adhesion represents an ideal strategy to combat bacterial pathogenesis because of its importance early in the infectious process, and it is also suitable for implementation as a prophylactic to prevent infection. Pathogens are capable of presenting multiple adhesins that can be expressed differentially to permit binding in specific sites and at particular times over the course of a complex infectious cycle. Thus, it may be difficult to develop a universal class of anti-adherence drugs. Nevertheless, several specific pathogenic adhesive strategies have emerged as hallmark requirements for virulence in certain infectious diseases that are immediate targets for drug discovery and development.

Some bacteria present non-fimbrial adhesins on their surface. These are expressed as monomeric proteins or protein complexes that assemble at the cell surface - for example, the Dr family of adhesins that are expressed by Escherichia coli and are important for adhesion in the intestine and urinary tract. Adhesive autotransporters represent a class of afimbrial adhesins that are expressed by various unrelated micro-organisms, including species of Rickettsia, Bordetella, Neisseria and Helicobacter and many members of the family Enterobacteriaceae. Haemophilus influenzae, a causative agent of sinusitis, bronchitis and otitis media, expresses an adhesive autotransporter called Hap that mediates binding to components of the host-cell extracellular matrix.

Most adhesins, however, are incorporated into hetero-polymeric extracellular fibres called pili or fimbriae. Many distinct virulence fibres have been described in Gram-negative organisms $^{25}$. Pili are also produced by Gram-positive organisms (reviewed in REF. ${ }^{26}$ ) and have been linked to virulence in Streptococcus pneumoniae ${ }^{27}$. Although bacterial fimbriae have diverse functions, many seem to be crucial to the binding and persistence of pathogenic microorganisms in the host (TABLE 1). In the following subsections, we review the importance of pilus-mediated adhesion by E. coli in the pathogenesis of urinary-tract infection (UTI) and discuss strategies to inhibit pilus biogenesis. We also describe the need for new approaches to prevent and treat UTI and examine the market considerations for antivirulence therapeutics.

\section{Denying access to uropathogens}

Uropathogenic E. coli (UPEC) are the major causative agents of UTI and engage in a coordinated and regulated genetic and molecular cascade to assemble type 1 and $\mathrm{P}$ pili, which are associated with infections of the bladder and kidney, respectively (reviewed in REF. ${ }^{28}$ ). Virtually all clinical UPEC isolates express type 1 pili $^{29}$. These are required to bind mannosecontaining host receptors, invade host bladder-epithelial (urothelial) cells ${ }^{30,31}$ and initiate a pathogenic cascade that involves several distinct phases as examined in the mouse cystitis model $^{32,33}$ and human UTIs ${ }^{34}$ (FIG. 1). Within urothe-lial cells, bacteria first replicate rapidly to form dense biofilm-like communities and are protected from the flow of urine and host defences 33,35 . UPEC eventually detach and then disperse, or flux, from the intracel-lular bacterial community (IBC) to initiate new rounds of IBC formation in other cells. Some fluxing bacteria form filaments, evade neutrophil phagocytosis and facilitate bacterial survival ${ }^{33,35}$. Even after acute infection is resolved, bacteria can remain within the bladder for many days to weeks, regardless of standard antibiotic treatments, and can be implicated in recurrent infection $^{36}$. It might be possible to target several factors in the pathogenic cascade to inhibit virulence. Type 1 pili represent an attractive drug target because the bottleneck of invasion and IBC formation selects for fitness in the urothelium and type 1 pili are required for both events. 
Two general strategies have emerged to inhibit pilus-mediated function. The first is adhesion specific and involves physically precluding pathogen binding to host cells. Carbohydrate derivatives of host ligands, for example, have showed efficacy in blocking the adhesive properties of both type 1 and $\mathrm{P}$ pili in biophysical and haemaglutination assays ${ }^{38-40}$. This approach can be readily extended to other adherent organisms by tailoring the anti-adhesive compounds to their receptor specificities in vivo. The goal of the second strategy is to interrupt pilus assembly, which also blocks pilus-mediated adhesion as well as invasion and intracellular biofilm formation.

Type 1 and $\mathrm{P}$ pili are both assembled by the chaperone-usher system 41 . Although the fim and pap operons, which are associated with type 1 and $\mathrm{P}$ pili, respectively, are the best studied of these systems, 17 additional chaperone-usher operons have been identified in sequenced $E$. coli genomes ${ }^{42}$. The chaperone-usher systems are also necessary for the assembly of extracellular adhesive organelles in a wide range of other pathogens, including species of Salmonella, Pseudomonas, Haemophilus, Klebsiella and Yersinia. Therefore, inhibitors of the chaperone-usher system may serve as broader-range therapeutics, an attractive feature that would enhance the marketability of an effective drug. Pilicides are a class of pilus inhibitors that target chaperone function and inhibit pilus biogenesis 43,44 . A new class of pilicides, based on a bi-cyclic 2-pyridone scaffold, inhibit both type 1 and $\mathrm{P}$ pili assembly in $E$. coli by targeting conserved regions on chaperones that are ubiquitous in the chaperone-usher pathways 45 (FIG. 2). These pilicides also inhibit biofilm formation in E. coli. The synthetic pilicides disrupt an essential protein-protein interaction between the chaperone and usher at a site that has been identified by x-ray crystallography. Thus, pilicides have the opportunity to work either at the level of attachment and invasion or the level of bacterial aggregation once they are inside the superficial facet cells that line the bladder lumen.

\section{Therapeutic outlook for UTIs}

The urinary tract is a common site of infection in humans, and UTIs result in more than 8 million outpatient visits per year in the United States and, in the year 2000, expended costs of US $\$ 3.5$ billion for evaluation and treatment ${ }^{46,47}$. Women are the most frequent sufferers a female has a 50\% chance of developing an acute UTI during her lifetime - and many experience recurrent infections. With advancing age and co-morbidities, UTI becomes progressively more common among both women and men, particularly in the context of urinary catheterization. Limited treatment options are available for patients with chronic and recurrent UTIs. Although these patients can be treated using prolonged courses of antibiotics, this radically disrupts the symbiotic host-microorganism balance and may be accompanied by the evolution of drug-resistant organisms in the urinary tract ${ }^{48}$. In addition, UTIs have a strong causal correlation with systemic infection and sepsis if antibiotic therapy is ineffective ${ }^{49}$. Because infection of the bladder is not limited to extra-cellular colonization, and can involve both the invasion of host cells and the subversion of host defences and other specific mechanisms, such as filamentation, to promote persistence and re-invasion, it may be essential to target key bottlenecks, such as type 1 pili expression and/or assembly. Current research efforts are underway to identify other candidate nodes in the network of these host-pathogen interactions.

The treatment of recurrent or chronic UTIs, in which intracellular bacterial reservoirs already exist, might require a synergistic therapy, such as combining a pilicide, for example, with a stimulator of the immune response or epithelial-cell renewal (to drive bacteria out of intracellular niches). Scientific research and new drug development for UTIs accompany a clear clinical demand, and are associated with large patient populations for clinical-stage development and the potential long-term profits that effective therapies will produce. We 
anticipate that drug-discovery and development efforts for UTIs and other chronic infections will increase markedly over the next 5-10 years.

\section{Bacterial toxins}

Toxin-powered pathogens can exert a devastating effect from a distance. For many infectious diseases, the clinical symptoms and cause of tissue damage can be attributed to the action of secreted bacterial toxins. Botulinum, anthrax, diphtheria, tetanus, cholera and Shiga toxins are produced by distinct bacterial pathogens, and each is a major cause of cellular malfunction and morbidity in afflicted individuals 50 . In addition, their extreme toxicity makes these toxins potential weapons for use in biological warfare or a terrorist attack. Multiple opportunities exist to prevent toxin damage to the host (FIG. 3).

\section{Targeting a toxin transcription factor}

Vibrio cholerae infection is characterized by severe diarrhoea and dehydration, which becomes life threatening if effective treatment of the symptoms is delayed. Cholera toxin provides $V$. cholerae with its hallmark virulence and triggers the debilitating symptoms of the disease by interacting with G proteins and cyclic AMP in the intestinal lining to interrupt proper ion transport, which results in massive fluid loss ${ }^{51}$. The potent toxin has been recognized by Hung and colleagues 52 as an ideal candidate for drug development, which, as resistance has emerged to the antibiotics of choice, ciprofloxacin and azithromycin, is particularly needed. The small molecule virstatin was discovered by screening for inhibitors of toxT gene expression. ToxT is a transcription factor that activates the gene transcription of both cholera toxin and another $V$. cholerae virulence factor, the toxin-co-regulated pilus ${ }^{52}$. Thus, virstatin inhibits choleraegene expression, the earliest step in toxin production.

Selective inhibition of gene expression is a general strategy that can be implemented for many virulence factors, as expression is controlled by the environment that is sensed by the organism. In the clinic, however, such a therapy may have a short window of opportunity to work. On the one hand, after an extended time, bacteria may reach high numbers and produce sufficient toxin to overwhelm the host, such that inhibition of toxin production alone may be too late. On the other hand, effective and selective therapeutics could be useful prophylactically in limiting epidemics.

\section{Neutralizing toxins using antibodies}

An antivirulence strategy has been the treatment of choice for the post-exposure treatment of tetanus, diphtheria and botulinum toxins. Antibodies against the toxins are administered to patients to attempt to neutralize toxins while infection is cleared ${ }^{53}$. In addition to simply neutralizing toxins, benefit to the host may be ascribed, in part, to a more sophisticated host response that includes the antibody-mediated recognition and potential clearance of pathogens and their toxic cargo, as reviewed elsewhere $22-24$. The neutralizing antibodies are typically obtained from the sera of immunized horses or humans, but the production of monoclonal antibodies is an attractive alternative. Many monoclonal-antibody therapies are already in use for preventing transplant rejection and oncological treatment; an antiviral monoclonal antibody, palivizumab, which prevents respiratory syncytial virus in children, was licensed in 1998.

Currently, adult cases of botulism, a rare infectious disease that is caused by Clostridium botulinum, are treated with an antitoxin that contains horse antibodies raised against type A, type $\mathrm{B}$ and/or type $\mathrm{E}$ strains of botulinum neurotoxins. This drug is available from the Centers for Disease Control and Prevention (CDC), United States, if specially requested by a physician. It is listed in the Official Monographs of the United States Pharmacopeia, even though it has 
never been examined in controlled human clinical trials. Owing to the equine antitoxin's potentially serious side effects, it has not typically been used to treat infants suffering from botulism. However, a landmark in antivirulence therapy occurred on 23 October 2003. The Food and Drug Administration in the United States licensed an antivirulence drug that contained antibotulinum-toxin antibodies produced from humans to the California Department of Health Services, based on their seminal clinical research that spanned approximately 15 years. A placebo-controlled clinical trial consisting of 122 infants with botulism demonstrated a profound clinical benefit for patients treated with human botulism immune globulin (BIG), subsequently named BabyBIG ${ }^{54}$. Clinical results showed a reduction in the length of hospital stay, duration of intensive care, duration of mechanical ventilation, duration of tube or intravenous feeding and hospital charges per patient. This remarkable clinical evidence strongly supports a treatment strategy of neutralizing bacterial toxins post-infection.

\section{Targeting toxin trafficking and function}

Antibody- neutralization strategies will fall short for some patients and infectious diseases. Toxins that are delivered through the type III secretion system (T3SS; discussed below), for example, are delivered directly into host cells, do not circulate globally and are not ideal candidates for antibody neutralization. The best defences against toxin-empowered pathogens that are encountered in the community, or as potential bioweapons, might require a better understanding of pathogenesis and toxin biochemistry. For many toxins, new research is needed to provide higher-resolution models of toxin trafficking than that presented in FIG. 3 (REF. 55). In this regard, chemical genetic approaches are driving the discovery of toxintrafficking inhibitors and, in turn, these small molecules are being used as tools, or molecular scalpels, to dissect the mechanistic details of toxin trafficking. Selective luciferase-based screening assays, for example, have identified lead compounds that inhibit the actions of $E$. coli's Shiga toxin once it has gained access to the host cell, and therefore permit protein synthesis ${ }^{56,57}$. These compounds stop the toxin in real time along its path from the cell surface to the endoplasmic reticulum, and provide a unique opportunity to examine toxin-transport processes in more detail. The ability to target toxins after they have entered host cells, but before they exercise their function, provides an additional opportunity in time and space to control the sequelae of toxin action.

Improved models of the assembly and function of anthrax toxin, produced by the Gram-positive Bacillus anthracis, provide several distinct checkpoints that can be targeted for interception ${ }^{55}$. Peptides and small-molecule inhibitors have been identified that bind to lethal factor (one of the three anthrax toxin components) and inhibit the in vitro enzymatic activity that is linked to pathogenesis in vivo ${ }^{58-60}$. Several molecules have been reported to block endosomal acidification, and so inhibit the conformational changes that are required for pore formation at the host-cell surface, and anthrax-toxin entry. Having multiple ways to target toxin-powered pathogens encourages the development of new and diverse therapeutics that promise to treat a large number of infectious diseases.

\section{Focus on bioterrorism}

The dangers that are associated with an anthrax bioterrorism threat were made clear in 2001 when $B$. anthracis was disseminated throughout the United States postal system leaving five dead and many ill. Anthrax toxins, along with botulinum toxins, are classified in the highest risk category of biological warfare agents by the $\mathrm{CDC}$, and nearly $\$ 6$ billion have been allocated by Project BioShield to develop and stockpile antibiotics, antitoxins and vaccines for these and other high-threat agents ${ }^{61}$. Vaccination efforts are not generally promoted, however, because the chance of exposure to any particular bioterrorism agent is remote. 
PharmAthene was founded in 2001 to develop technologies and products to address these biosecurity needs. Their new antivirulence drug, Valortim, is a human monoclonal antibody that has demonstrated prophylactic and, separately, post-infection protection against $B$. anthracis toxins in rabbit and non-human primate models ${ }^{62}$. It has successfully completed Phase I safety and pharmacokinetic evaluation. In 2006, Cangene Pharmaceuticals received a 5-year, \$362-million contract from Project BioShield to develop and produce 200,000 doses of a potentially improved botulinum antitoxin, a heptavalent antitoxin that is derived from horses (containing antibodies to 7 toxin subtypes), because of its potential use as a bioterror agent. Its initial order was formally received into the United States Strategic National Stockpile in September 2007.

\section{Scientific leaps and commercialization hurdles}

Antibody-based toxin neutralization (discussed above), could be considered to be a simple approach to target toxin-based virulence that does not require a high- resolution roadmap detailing toxin trafficking and sub-cellular targets. However, toxin-associated diseases are often not that simple. They can be extremely complex, with cascading symptoms that may or may not lead to life-threatening complications. Consequently, the Anti-Infective Drugs Advisory Committee meeting held on 12 April 2007, when considering the operational details of executing clinical trials to demonstrate the effectiveness of a new antivirulence therapy, emphasized the pitfalls and hurdles that might impede the commercialization of any antivirulence therapy that targets small patient populations ${ }^{63}$. At this meeting, research results were presented for two separate monoclonal antibodies that are under development to treat Shiga-toxin-producing bacterial infections. Shiga toxin is produced by Shigella dysenteriae and Shiga-toxin-producing E. coli (STEC), which includes the prototype strain E. coli O157:H7 that has caused several food-borne outbreaks around the world. The toxin is secreted into the host cell and inhibits host protein synthesis, which can lead to multiple clinical manifestations, such as gastrointestinal disease, bloody diarrhoea, the destruction of red blood cells and platelets, and haemolytic uraemic syndrome ${ }^{64}$. Treatment using antibiotics is controversial owing to the bolus of toxin that could be released as bacteria die, which, potentially, could overwhelm the patient's defences.

Even though evidence of efficacy from animal models was presented at this meeting, representatives from companies and the physicians on the advisory committee were unable to successfully construct an appropriate clinical-trial design to evaluate these potential drugs. The two main challenges for the successful completion of clinical trials seem to be, first, that primary endpoints for this specific disease in humans are unclear and, second, that achieving statistical significance may not be attainable because the low incidence of this disease prevents adequate patient enrolment. The findings of this meeting strongly suggest that researchers should target the virulence mechanisms that are involved in infectious diseases with clear and measurable clinical end-points in sufficiently large patient populations. These realities of commercialization seem to make developing drugs against STEC and other complicated diseases that affect small patient populations less attractive compared with diseases that affect large patient populations, such as UTIs and chronic ear and sinus infections. These hurdles will accompany the development of future antivirulence products, and imminent decisions surrounding the potential Shiga drugs will influence the course of future endeavours.

\section{Type III secretion}

The Shiga and cholera toxins discussed above are exported by type II secretion, a general secretion system through which extracellular enzymes are also secreted 65 . However, other pathogens deliver their virulent cargo using the T3SS. This system orchestrates the export and delivery of virulence factors, or effector proteins, from the bacterial cytoplasm across the inner membrane, the peptidoglycan and outer membrane and, finally, through the host-cell plasma 
membrane, directly into the host-cell cytosol in the manner of a molecular syringe ${ }^{66}$. The T3SS machinery is used by many Gram-negative pathogens, such as E. coli, Salmonella enterica serovar Typhimurium, Shigella flexneri, Pseudomonas aeruginosa and species of Yersinia and Chlamydia. Yersinia species, such as Yersinia pestis, the causative agent of plague, inject effector proteins called YOPs (Yersinia outer proteins) through the T3SS into host cells to inhibit the host immune response and help them to evade a potent host response and subsequent clearance 67,68 .

The conserved elements in the T3SS machinery that allow the interchange of T3SS components among some bacteria 69,70 suggest that it may be possible to design broad-range T3SS inhibitors that are effective in treating disparate pathogens, regardless of the unique effector proteins that they deliver. Small-molecule inhibitors of the T3SS have been described in $\underline{\text { Yersinia pseudotuberculosis }}^{71,72}$. More recently, the discovery that small-molecule T3SS inhibitors in Yersinia spp. inhibit the T3SS in Chlamydia trachomatis supports the notion of developing broader-range T3SS inhibitors. Interestingly, the role of the T3SS in the pathogenesis of Chlamydia spp. infection is not well understood, owing, in part, to the inability to manipulate Chlamydia spp. genetically. However, in the previously mentioned study, the small-molecule inhibitors were recruited using chemical genetics to assess the potential importance of the T3SS in C. trachomatis infection. Treatment with the T3SS inhibitor did inhibit the in vivo pathogenic cascade and resulted in a decrease in secreted effector proteins, suggesting that the T3SS was inhibited and is essential to the $C$. trachomatis infectious cycle $^{73-75}$. These T3SS inhibitors will be a useful tool for further study of the T3SS in Chlamydia spp., and might represent target leads for future therapeutics.

\section{Biofilms and chronic infections}

Biofilms are complex, organized bacterial assemblies that are highly resistant to antibiotics and host defences. Biofilms can form on abiotic surfaces, such as surgical implants and catheters, and result in persistent infections that are difficult to treat, thereby leading to further health complications and longer hospital stays. Bacteria in chronic wounds, which are particularly prevalent in the elderly and diabetic populations, form biofilms that prevent proper healing 76 . Indeed, the ability of bacteria to persist robustly in biofilm communities in the human host and the environment, even against antibiotic pressure, is a fundamental observation that extends across the field of microbiology and poses serious challenges to the control and treatment of chronic infectious disease.

The intracellular biofilms that are formed by UPEC in the urinary tract after their invasion of the bladder epithelium and smaller numbers of quiescent bacteria that are harboured in underlying reservoirs are implicated in the aetiology of recurrent UTIs ${ }^{36}$. Clinical studies of recurrent infection of the middle- ear tissue in children indicate that chronic otitis media stems from a persistent biofilm following the first infection ${ }^{77}$. Helicobacter pylori biofilms have been documented in the biopsied gastric mucosa of patients suffering from gastric ulcers, and it has been suggested that the ulcers are manifestations of these biofilms ${ }^{78}$. In addition, patients with cystic fibrosis are threatened by $P$. aeruginosa biofilm-mediated chronic lung infections, which are responsible for the high morbidity and mortality of patients with cystic fibrosis 79 , 80 .

Several strategies have emerged to inhibit biofilm formation and eradicate established biofilms. These include, but are not limited to: preventing the initial adherence of bacteria to either a surface or another bacterium (discussed above); interrupting QS mechanisms that are required for the gene expression of biofilm components (discussed below); inhibiting the biosynthesis of the integral polysaccharide and proteinaceous extracellular components of the biofilm 
matrix 81 ; and identifying or tailoring enzymes that can degrade the biofilm matrix, thereby rendering bacteria accessible to traditional antibiotics and/or immune clearance.

If we examine the anti-infective marketplace, the health and economic impact of multidrugresistant organisms, particularly in the hospital setting, is driving the primary market for drug development. However, markets that encompass recurrent and chronic bacterial infections consist of significantly larger patient populations that have considerable unmet clinical needs and provide attractive opportunities for drug-development efforts. Effective biofilm inhibitors could dramatically change treatment regimens for many infectious diseases and benefit large patient populations.

\section{Quorum sensing}

QS is the illustrative term that is used to describe the chemical signalling that takes place among bacteria to keep track of their cellular density. QS is mediated by the production and subsequent recognition of small molecules called autoinducers, and is used to coordinate gene expression and regulate the numerous processes that are involved in community behaviour and virulence, for example, motility and biofilm formation (reviewed in REFS 82,83). In nature, the red seaweed Delisea pulchra produces chemical compounds called furanones that intercept QS signals and prevent microbial colonization 84,85 . This natural phenomenon has inspired the search for compounds that selectively inhibit QS, biofilm formation and the virulence of human pathogens during infection 86 .

P. aeruginosa is frequently encountered in noso-comial infections and lung infections in patients with cystic fibrosis, and produces more than 30 QS-regulated virulence factors. Numerous studies, predominantly carried out over the past 5 years, strongly support the notion that QS inhibitors, including isolated and synthetic furanones, can be effective in treating bacterial infections in vivo 87,88 . Notably, $P$. aeruginosa biofilms exhibit increased susceptibility to sodium dodecyl sulphate and the antibiotic tobramycin if treated with a synthetic furanone, compound C-30 (REF. 87). In a mouse pulmonary infection model, treatment with compound C-30 resulted in increased bacterial clearance ${ }^{87}$. Thus, inhibition of QS can increase the susceptibility of biofilm bacteria to host defences and antibacterial agents. Givskov and colleagues ${ }^{87}$ have suggested that direct targeting of QS might be effective as an early prophylactic treatment of individuals who have $P$. aeruginosa infections in the lungs, on implants or in wounds.

Other examples underscore the challenge of interrupting the right signals at the right times to reduce bacterial virulence in the host. A non-native $N$-acylated-L-homoserine lactone, for example, was recently discovered that can either inhibit or strongly induce QS in the marine symbiont Vibrio fischeri, depending on the molecule concentration ${ }^{89}$. Results from a panel of compounds in the same family elicited varied QS responses, which implies that the rational design of modified QS antagonists or agonists may not be straightforward; new insights are needed to fully understand these responses. In addition, redundancies among QS systems can render inhibitors of a single system ineffective. Indeed, two of the three parallel QS systems in $V$. cholerae are dispensable for host colonization and the production of two hallmark virulence factors, cholera toxin and the toxin co-regulated pilus ${ }^{90}$. QS circuits are being examined in numerous models to determine if similar redundancies exist and to what extent individual chemical signals influence multiple QS pathways. The generation of QS circuit diagrams may reveal viable drug targets and small molecules that may prove useful as scalpels to probe the roles of QS in different systems. 


\section{Two-component response systems}

A central requirement of bacterial virulence is the ability to express subsets of genes in response to signals that are specific for a particular environment. Two-component response systems (TCRSs) seem to be the dominant mechanism by which bacteria and fungi respond to their environment ${ }^{91}$. TCRSs can control host invasion, drug resistance, motility, phosphate uptake, osmoregulation, nitrogen fixation and other functions. More than 4,000 TCRSs have been identified in approximately 400 sequenced bacterial genomes ${ }^{92,93}$. Selected TCRSs that regulate virulence are provided in TABLE 2.

The essence of signal transduction lies in the recognition and interpretation of environmental signals that are related to host infection, and conversion of those signals into specific proteinprotein interactions and transcriptional activation ${ }^{94}$. Bacterial transduction systems generally consist of receiver domains that are covalently linked to effector domains (FIG. 4). Specifically, each TCRS is composed of a histidine kinase that is activated by extracellular signals in the host environment and a response regulator that, in turn, transmits the signal to the intracellular target to modulate the gene expression of virulence factors. The interfaces between response regulators and their protein modulators can be targeted to prevent phosphorylation and/or activation, as well as the interfaces of homodimer formation of activated response regulators that are required for the control of gene expression. Broad-spectrum inhibitors could nonselectively target the TCRSs that are common to many bacteria. More selective inhibitors could target the interaction of specific phosphorylated response regulators to prevent expression of a specific virulence gene 95 .

A TCRS is an integral component of the QS system in Gram-positive bacteria that responds to bacterial density, and is named $a g r$ for accessory gene regulator. The global regulator $a g r$ controls the expression of most virulence genes in staphylococci and is activated by secreted autoinducing peptides (AIPs) called thiolactones that comprise 7-10 amino acids 96 . AgrC and AgrA are the histidine-kinase sensor and response regulator, respectively, of the TCRS. AIP thiolactones have been suggested as leads for the development of S. aureus therapeutics that are urgently needed, owing to the fact that nosocomial and community-acquired MRSA infections are on the rise. The agr system also functions to downregulate factors that are important in biofilm formation, and agr dysfunction is associated with increased biofilm production ${ }^{97}$. As discussed above, a more detailed understanding of the organism's control networks is needed to identify the ideal genetic or molecular checkpoints that need to be targeted to reduce virulence in the host.

The prevention of virulence mechanisms that promote antibiotic tolerance could also improve the efficacy of current antibiotics, and, particularly, slow down the processes that lead to drug resistance. Several TCRSs are responsible for inducing the gene expression that confers bacterial tolerance to antibiotics. Vancomycin resistance, for example, is triggered by the VanR-VanS TCRS. VanS detects the glycopeptide antibiotic and VanR activates the expression of the enzymes VanA, VanH and VanX, all of which are required for resistance $^{98,99}$ (reviewed in REF. ${ }^{11}$ ). The TCRS proteins and the three enzymes cooperate to synthesize an altered peptidoglycan framework that is tolerant to vancomycin exposure, which is a hallmark of the vancomycin-resistant enterococci and vancomycin-resistant $S$. aureus that have emerged in the clinic.

\section{Conclusions and perspectives}

This era may come to be remembered as one in which infectious diseases made a dramatic worldwide resurgence, owing to the rise of antibiotic resistance and emergence of new diseases. We must increase the number of available therapeutics, protect the effectiveness of current 
antibiotics and, importantly, decrease further pressure for the evolution of new drug-resistance mechanisms. Neutralizing bacterial toxins by using antibodies has emerged as the mostpursued antivirulence therapeutic strategy in industry, with at least six candidates undergoing clinical trials. The initial successes of these antitoxins seem to provide empirical evidence that supports increased research into other antivirulence approaches. Therefore, it is imperative that we determine the mechanisms of virulence and the consequences of host-pathogen interactions from both the pathogen and host perspective. Insights regarding bacterial virulence and pathogenesis have emerged, yet many crucial questions remain unanswered. Major breakthroughs will require multi-disciplinary tools from bacterial and host genetics, structural biology and in vivo imaging, animal models, cell biology, immunology, biochemistry, chemical genetics, functional genomics and systems biology. Atomic-level details of the structural interactions at host-pathogen interfaces are vital for the discovery of effective antivirulence drugs by structure-based drug design for proposed targets.

In battling infection, disabling microbial virulence in vivo could shift the advantage to the host and render bacteria impaired in defeating host defences. Alternatively, antivirulence drugs could be used in combination therapy, in which bacterial clearance is mediated by standard antibiotics and the symptoms of virulence are suppressed. The effective deployment of antivirulence drugs will require rapid diagnosis in the clinic of the organism (or organisms) that is responsible for infection and may include profiling of its virulence gene or genes 100 . Such routine and rapid diagnosis would also improve the use of standard antibiotics, and represents a necessary investment as medicine improves and becomes more personalized.

We must succeed in this continuous war against infectious disease. A recent review of the antibacterial drug-development efforts by GlaxoSmithKline reveals, in essence, that we have underestimated our opponent and that arrogance has dominated the search for new antibiotics ${ }^{101}$. Regaining our competitive advantage will require us to see beyond what we currently accept as dogma. It will also depend on the removal of perceived obstacles to infuse the industry with new opportunities. We need to accept that a one-drug-fits-all strategy will probably fail. We also need to consider each specific disease, pathogen and virulence mechanism, and combine the strengths of synergistic therapies to minimize the evolution by pathogens of resistance.

\section{Acknowledgements}

The authors acknowledge funding from the National Institutes of Health to S.J.H. (grant numbers P50-ORWH/ DK64540, R01AI029549, R01AI048689 and R01DK51406), G.R.M. (grant number R01GM068460) and L.C. (grant number T32A107172).

\section{References}

1. Alekshun MN, Levy SB. Molecular mechanisms of antibacterial multidrug resistance. Cell 2007;128:1037-1050. [PubMed: 17382878]

2. Livermore DM. Minimising antibiotic resistance. Lancet Infect Dis 2005;5:450-459. [PubMed: 15978531]

3. Palumbi SR. Humans as the world's greatest evolutionary force. Science 2001;293:1786-1790. [PubMed: 11546863]

4. Vicente M, et al. The fallacies of hope: will we discover new antibiotics to combat pathogenic bacteria in time? FEMS Microbiol Rev 2006;30:841-852. [PubMed: 17064283]

5. Levy SB, Marshall B. Antibacterial resistance worldwide: causes, challenges and responses. Nature Med 2004;10:S122-S129. [PubMed: 15577930]

6. Crowley PJ, Martini LG. Formulation design: new drugs from old. Drug Discov Today: Therapeutic Strategies 2004;1:537-542. 
7. Projan SJ. Why is big Pharma getting out of antibacterial drug discovery? Curr Opin Microbiol 2003;6:427-430. [PubMed: 14572532]

8. Fernandes P. Antibacterial discovery and development - the failure of success? Nature Biotechnol 2006;24:1497-1503. [PubMed: 17160049]

9. Talbot GH, et al. Bad bugs need drugs: an update on the development pipeline from the antimicrobial availability task force of the infectious diseases society of America. Clin Infect Dis 2006;42:657-668. [PubMed: 16447111]

10. Blount KF, Wang JX, Lim J, Sudarsan N, Breaker RR. Antibacterial lysine analogs that target lysine riboswitches. Nature Chem Biol 2007;3:44-49. [PubMed: 17143270]Identified lysine analogues that bind to lysine riboswitches in vitro and inhibit the growth of Bacillus subtilis. Also discusses the general importance of riboswitches and their suitability as antibacterial drug targets.

11. Wright GD. The antibiotic resistome: the nexus of chemical and genetic diversity. Nature Rev Microbiol 2007;5:175-186. [PubMed: 17277795]

12. Mwangi MM, et al. Tracking the in vivo evolution of multidrug resistance in Staphylococcus aureus by whole-genome sequencing. Proc Natl Acad Sci USA 2007;104:9451-9456. [PubMed: 17517606]

13. Finlay BB, Falkow S. Common themes in microbial pathogenicity revisited. Microbiol Mol Biol Rev 1997;61:136-169. [PubMed: 9184008]

14. Lee YM, Almqvist F, Hultgren SJ. Targeting virulence for antimicrobial chemotherapy. Curr Opin Pharmacol 2003;3:513-519. [PubMed: 14559097]

15. Marra A. Can virulence factors be viable antibacterial targets? Expert Rev Anti Infect Ther 2004;2:6172. [PubMed: 15482172]

16. Savage DC. Microbial ecology of the gastrointestinal tract. Annu Rev Microbiol 1977;31:107-133. [PubMed: 334036]

17. Backhed F, et al. The gut microbiota as an environmental factor that regulates fat storage. Proc Natl Acad Sci USA 2004;101:15718-15723. [PubMed: 15505215]

18. Miller JF, Mekalanos JJ, Falkow S. Coordinate regulation and sensory transduction in the control of bacterial virulence. Science 1989;243:916-922. [PubMed: 2537530]A perspective that emphasizes the need to understand coordinate regulation and sensory transduction to understand the events that occur during the pathogenesis of infectious disease.

19. Virgin HW. In vivo veritas: pathogenesis of infection as it actually happens. Nature Immunol 2007;8:1143-1147. [PubMed: 17952037]An overview and perspective of the benefits that are ascribed to bridging the disciplines of microbiology and immunology, including lessons from Heisenberg.

20. Moxon ER, Rainey PB, Nowak MA, Lenski RE. Adaptive evolution of highly mutable loci in pathogenic bacteria. Curr Biol 1994;4:24-33. [PubMed: 7922307]

21. Monack DM, Mueller A, Falkow S. Persistent bacterial infections: the interface of the pathogen and the host immune system. Nature Rev Microbiol 2004;2:747-765. [PubMed: 15372085]Review and consideration of the dynamic cross-talk at the host-pathogen interface and the delicate balance between protective immunity and immunopathology.

22. Kaufmann SHE. The contribution of immunology to the rational design of novel antibacterial vaccines. Nature Rev Microbiol 2007;5:491-504. [PubMed: 17558425]

23. Kokai-Kun JF, Mond JJ. Antibody therapy for treatment or prevention of infectious diseases. Drug Discov Today: Therapeutic Strategies 2004;1:475-481.

24. Pirofski LA, Casadevall A. Immunomodulators as an antimicrobial tool. Curr Opin Microbiol 2006;9:489-495. [PubMed: 16931122]

25. Hung DL, Hultgren SJ. Pilus biogenesis via the chaperone/usher pathway: an integration of structure and function. J Struct Biol 1998;124:201-220. [PubMed: 10049807]

26. Telford JL, Barocchi Mle A, Margarit I, Rappuoli R, Grandi G. Pili in Gram-positive pathogens. Nature Rev Microbiol 2006;4:509-519. [PubMed: 16778837]

27. Barocchi MA, et al. A pneumococcal pilus influences virulence and host inflammatory responses. Proc Natl Acad Sci USA 2006;103:2857-2862. [PubMed: 16481624]

28. Mulvey MA. Adhesion and entry of uropathogenic Escherichia coli. Cell Microbiol 2002;4:257-271. [PubMed: 12027955] 
29. Garofalo CK, et al. Escherichia coli from urine of female patients with urinary tract infections is competent for intracellular bacterial community formation. Infect Immun 2007;75:52-60. [PubMed: 17074856]

30. Martinez JJ, Mulvey MA, Schilling JD, Pinkner JS, Hultgren SJ. Type 1 pilus-mediated bacterial invasion of bladder epithelial cells. EMBO J 2000;19:2803-2812. [PubMed: 10856226]

31. Sauer FG, Mulvey MA, Schilling JD, Martinez JJ, Hultgren SJ. Bacterial pili: molecular mechanisms of pathogenesis. Curr Opin Microbiol 2000;3:65-72. [PubMed: 10679419]

32. Anderson GG, et al. Intracellular bacterial biofilm-like pods in urinary tract infections. Science 2003;301:105-107. [PubMed: 12843396]

33. Justice SS, et al. Differentiation and developmental pathways of uropathogenic Escherichia coli in urinary tract pathogenesis. Proc Natl Acad Sci USA 2004;101:1333-1338. [PubMed: 14739341] Revealed the multi-step E. coli pathogenic cascade using time-lapse fluorescence videomicroscopy to observe infected mouse-bladder explants.

34. Rosen Da HT, Stamm WE, Humphrey PA, Hultgren SJ. Detection of intracellular bacterial communities in human urinary tract infection. PLoS Med. (in the press)

35. Mulvey MA, et al. Induction and evasion of host defenses by type 1-piliated uropathogenic Escherichia coli. Science 1998;282:1494-1497. [PubMed: 9822381]

36. Mysorekar IU, Hultgren SJ. Mechanisms of uropathogenic Escherichia coli persistence and eradication from the urinary tract. Proc Natl Acad Sci USA 2006;103:14170-14175. [PubMed: 16968784]

37. Wright KJ, Seed PC, Hultgren SJ. Development of intracellular bacterial communities of uropathogenic Escherichia coli depends on type 1 pili. Cell Microbiol 2007;9:2230-2241. [PubMed: 17490405]

38. Kihlberg J, Magnusson G. Use of carbohydrates and peptides in studies of adhesion of pathogenic bacteria and in efforts to generate carbohydrate-specific T cells. Pure Appl Chem 1996;68:21192128.

39. Firon N, Ashkenazi S, Mirelman D, Ofek I, Sharon N. Aromatic alpha-glycosides of mannose are powerful inhibitors of the adherence of type 1 fimbriated Escherichia coli to yeast and intestinal epithelial cells. Infect Immun 1987;55:472-476. [PubMed: 3542836]

40. Bouckaert J, et al. Receptor binding studies disclose a novel class of high-affinity inhibitors of the Escherichia coli FimH adhesin. Mol Microbiol 2005;55:441-455. [PubMed: 15659162]

41. Sauer FG, Remaut H, Hultgren SJ, Waksman G. Fiber assembly by the chaperone-usher pathway. Biochim Biophys Acta 2004;1694:259-267. [PubMed: 15546670]

42. Chen SL, et al. Identification of genes subject to positive selection in uropathogenic strains of Escherichia coli: a comparative genomics approach. Proc Natl Acad Sci USA 2006;103:5977-5982. [PubMed: 16585510]

43. Svensson A, et al. Design and evaluation of pilicides: potential novel antibacterial agents directed against uropathogenic Escherichia coli. Chembiochem 2001;2:915-918. [PubMed: 11948880]

44. Larsson A, et al. Multivariate design, synthesis, and biological evaluation of peptide inhibitors of FimC/FimH protein-protein interactions in uropathogenic Escherichia coli. J Med Chem 2005;48:935-945. [PubMed: 15715464]

45. Pinkner JS, et al. Rationally designed small compounds inhibit pilus biogenesis in uropathogenic bacteria. Proc Natl Acad Sci USA 2006;103:17897-17902. [PubMed: 17098869]

46. Report No. 04-5512, 153-183. US Government Printing Office; Washington DC: 2004.

47. Report No. 04-5512, 187-209. US Government Printing Office; Washington DC: 2004.

48. Ronald AR, et al. Urinary tract infection in adults: research priorities and strategies. Int $\mathrm{J}$ Antimicrob Agents 2001;17:343-348. [PubMed: 11295419]

49. Acharya VN. Urinary tract infection - a dangerous and unrecognised forerunner of systemic sepsis. J Postgrad Med 1992;38:52-54. [PubMed: 1432825]

50. Schmitt CK, Meysick KC, O'Brien AD. Bacterial toxins: friends or foes? Emerg Infect Dis 1999;5:224-234. [PubMed: 10221874]

51. Spangler BD. Structure and function of cholera toxin and the related Escherichia coli heat-labile enterotoxin. Microbiol Rev 1992;56:622-647. [PubMed: 1480112] 
52. Hung DT, Shakhnovich EA, Pierson E, Mekalanos JJ. Small-molecule inhibitor of Vibrio cholerae virulence and intestinal colonization. Science 2005;310:670-674. [PubMed: 16223984]

53. Keller MA, Stiehm ER. Passive immunity in prevention and treatment of infectious diseases. Clin Microbiol Rev 2000;13:602-614. [PubMed: 11023960]

54. Arnon SS, Schechter R, Maslanka SE, Jewell NP, Hatheway CL. Human botulism immune globulin for the treatment of infant botulism. N Engl J Med 2006;354:462-471. [PubMed: 16452558]

55. Young JA, Collier RJ. Anthrax toxin: receptor binding, internalization, pore formation, and translocation. Annu Rev Biochem 2007;76:243-265. [PubMed: 17335404]Describes the structural basis and molecular mechanisms of the anthrax toxin and provides insight into toxin function.

56. Saenz JB, Doggett TA, Haslam DB. Identification and characterization of small molecules that inhibit intracellular toxin transport. Infect Immun 2007;75:4552-4561. [PubMed: 17576758]

57. Zhao L, Haslam DB. A quantitative and highly sensitive luciferase-based assay for bacterial toxins that inhibit protein synthesis. J Med Microbiol 2005;54:1023-1030. [PubMed: 16192432]

58. Tonello F, Seveso M, Marin O, Mock M, Montecucco C. Screening inhibitors of anthrax lethal factor. Nature 2002;418:386. [PubMed: 12140548]

59. Panchal RG, et al. Identification of small molecule inhibitors of anthrax lethal factor. Nature Struct Mol Biol 2004;11:67-72. [PubMed: 14718925]

60. Turk BE, et al. The structural basis for substrate and inhibitor selectivity of the anthrax lethal factor. Nature Struct Mol Biol 2004;11:60-66. [PubMed: 14718924]

61. Russell PK. Project BioShield: what it is, why it is needed, and its accomplishments so far. Clin Infect Dis 2007;45:S68-S72. [PubMed: 17582574]

62. US Securities and Exchange Commission (SEC). Pharmathene, Inc. Form 10-Q, Quarter Ended September 30, Commission File Number 001-32587. 2007. SEC web site [online], http:// www.sec.gov/Archives/edgar/data/1326190/000110465907083136/ a07-29212_110q.htm\#Item2_103948

63. Food and Drug Administration Center for Drug Evaluation and Research. Summary Minutes of the Anti-Infective Drugs Advisory Committee on April 12, 2007. 2007. [online], http://www.fda.gov/ ohrms/dockets/AC/07/minutes/2007-4286m1.pdf

64. Gyles CL. Shiga toxin-producing Escherichia coli: an overview. J Anim Sci 2007;85:E45-E62. [PubMed: 17085726]

65. Sandkvist M, et al. General secretion pathway (eps) genes required for toxin secretion and outer membrane biogenesis in Vibrio cholerae. J Bacteriol 1997;179:6994-7003. [PubMed: 9371445]

66. Cornelis GR. The type III secretion injectisome. Nature Rev Microbiol 2006;4:811-825. [PubMed: 17041629]

67. Cornelis GR, Wolf-Watz H. The Yersinia Yop virulon: a bacterial system for subverting eukaryotic cells. Mol Microbiol 1997;23:861-867. [PubMed: 9076724]

68. Cornelis GR. Yersinia type III secretion: send in the effectors. J Cell Biol 2002;158:401-408. [PubMed: 12163464]

69. Cornelis GR, Van Gijsegem F. Assembly and function of type III secretory systems. Annu Rev Microbiol 2000;54:735-774. [PubMed: 11018143]

70. Rosqvist R, Hakansson S, Forsberg A, Wolf-Watz H. Functional conservation of the secretion and translocation machinery for virulence proteins of yersiniae, salmonellae and shigellae. EMBO J 1995;14:4187-4195. [PubMed: 7556059]

71. Kauppi AM, Nordfelth R, Uvell H, Wolf-Watz H, Elofsson M. Targeting bacterial virulence: inhibitors of type III secretion in Yersinia. Chem Biol 2003;10:241-249. [PubMed: 12670538]

72. Nordfelth R, Kauppi AM, Norberg HA, Wolf-Watz H, Elofsson M. Small-molecule inhibitors specifically targeting type III secretion. Infect Immun 2005;73:3104-3114. [PubMed: 15845518]

73. Wolf K, et al. Treatment of Chlamydia trachomatis with a small molecule inhibitor of the Yersinia type III secretion system disrupts progression of the chlamydial developmental cycle. Mol Microbiol 2006;61:1543-1555. [PubMed: 16968227]

74. Muschiol S, et al. A small-molecule inhibitor of type III secretion inhibits different stages of the infectious cycle of Chlamydia trachomatis. Proc Natl Acad Sci USA 2006;103:14566-14571. [PubMed: 16973741]An elegant application of chemical genetics to microbial pathogenesis. A small 
molecule that was identified as a T3SS inhibitor in Yersinia spp. inhibited virulence of $C$. trachomatis, which supports the notion that the T3SS is important in C. trachomatis pathogenesis.

75. Bailey L, et al. Small molecule inhibitors of type III secretion in Yersinia block the Chlamydia pneumoniae infection cycle. FEBS Lett 2007;581:587-595. [PubMed: 17257594]

76. Saye DE. Recurring and antimicrobial-resistant infections: considering the potential role of biofilms in clinical practice. Ostomy Wound Manage 2007;53:46-62. [PubMed: 17449916]

77. Hall-Stoodley L, et al. Direct detection of bacterial biofilms on the middle-ear mucosa of children with chronic otitis media. JAMA 2006;296:202-211. [PubMed: 16835426]

78. Carron MA, Tran VR, Sugawa C, Coticchia JM. Identification of Helicobacter pylori biofilms in human gastric mucosa. J Gastrointest Surg 2006;10:712-717. [PubMed: 16713544]

79. Lam J, Chan R, Lam K, Costerton JW. Production of mucoid microcolonies by Pseudomonas aeruginosa within infected lungs in cystic fibrosis. Infect Immun 1980;28:546-556. [PubMed: 6772562]

80. Singh PK, et al. Quorum-sensing signals indicate that cystic fibrosis lungs are infected with bacterial biofilms. Nature 2000;407:762-764. [PubMed: 11048725]

81. Benghezal M, et al. Inhibitors of bacterial virulence identified in a surrogate host model. Cell Microbiol 2007;9:1336-1342. [PubMed: 17474906]

82. Keller L, Surette MG. Communication in bacteria: an ecological and evolutionary perspective. Nature Rev Microbiol 2006;4:249-258. [PubMed: 16501584]A holistic perspective of the potential roles of QS signals, from a cooperative to the battleground

83. Bassler BL, Losick R. Bacterially speaking. Cell 2006;125:237-246. [PubMed: 16630813]A creative composition and a lively review of the business of bacterial communication.

84. Kjelleberg S, et al. Do marine natural products interfere with prokaryotic AHL regulatory systems? Aquat Microb Ecol 1997;13:85-93.

85. Manefield M, et al. Evidence that halogenated furanones from Delisea pulchra inhibit acylated homoserine lactone (AHL)-mediated gene expression by displacing the AHL signal from its receptor protein [in process citation]. Microbiology 1999;145:283-291. [PubMed: 10075410]

86. Higgins DA, et al. The major Vibrio cholerae autoinducer and its role in virulence factor production. Nature Nov;2007 1410.1038/nature06284

87. Hentzer M, et al. Attenuation of Pseudomonas aeruginosa virulence by quorum sensing inhibitors. EMBO J 2003;22:3803-3815. [PubMed: 12881415]

88. Bjarnsholt T, Givskov M. Quorum-sensing blockade as a strategy for enhancing host defences against bacterial pathogens. Phil Trans R Soc Lond B 2007;362:1213-1222. [PubMed: 17360273]

89. Geske GD, O’Neill JC, Blackwell HE. $N$-phenylacetanoyl-L-homoserine lactones can strongly antagonize or superagonize quorum sensing in Vibrio fischeri. ACS Chem Biol 2007;2:315-319. [PubMed: 17480049]Identified a non-native $N$-acylated-L-homoserine lactone that can either inhibit or strongly induce QS in the marine symbiont $V$. fischeri, depending on the molecule concentration.

90. Miller MB, Skorupski K, Lenz DH, Taylor RK, Bassler BL. Parallel quorum sensing systems converge to regulate virulence in Vibrio cholerae. Cell 2002;110:303-314. [PubMed: 12176318]Revealed the redundant QS capacity in $V$. cholerae and discusses implications in terms of $V$. cholerae pathogenicity.

91. Wadhams GH, Armitage JP. Making sense of it all: bacterial chemotaxis. Nature Rev Mol Cell Biol 2004;5:1024-1037. [PubMed: 15573139]

92. Galperin MY. Structural classification of bacterial response regulators: diversity of output domains and domain combinations. J Bacteriol 2006;188:4169-4182. [PubMed: 16740923]

93. Ulrich LE, Zhulin IB. MiST: a microbial signal transduction database. Nucleic Acids Res 2007;35:D386-D390. [PubMed: 17135192]

94. Mascher T, Helmann JD, Unden G. Stimulus perception in bacterial signal-transducing histidine kinases. Microbiol Mol Biol Rev 2006;70:910-938. [PubMed: 17158704]

95. Barrett JF, Hoch JA. Two-component signal transduction as a target for microbial anti-infective therapy. Antimicrob Agents Chemother 1998;42:1529-1536. [PubMed: 9660978] 
96. Mayville P, et al. Structure-activity analysis of synthetic autoinducing thiolactone peptides from Staphylococcus aureus responsible for virulence. Proc Natl Acad Sci USA 1999;96:1218-1223. [PubMed: 9990004]

97. Otto M. Quorum-sensing control in Staphylococci — a target for antimicrobial drug therapy? FEMS Microbiol Lett 2004;241:135-141. [PubMed: 15598524]

98. Arthur M, Molinas C, Courvalin P. The VanS-VanR two-component regulatory system controls synthesis of depsipeptide peptidoglycan precursors in Enterococcus faecium BM4147. J Bacteriol 1992;174:2582-2591. [PubMed: 1556077]

99. Evers S, Courvalin P. Regulation of VanB-type vancomycin resistance gene expression by the VanS (B)-VanR (B) two-component regulatory system in Enterococcus faecalis V583. J Bacteriol 1996;178:1302-1309. [PubMed: 8631706]

100. Sintchenko V, Iredell JR, Gilbert GL. Pathogen profiling for disease management and surveillance. Nature Rev Microbiol 2007;5:464-470. [PubMed: 17487146]

101. Payne DJ, Gwynn MN, Holmes DJ, Pompliano DL. Drugs for bad bugs: confronting the challenges of antibacterial discovery. Nature Rev Drug Discov 2007;6:29-40. [PubMed: 17159923]

102. Jones $\mathrm{CH}$, et al. FimH adhesin of type 1 pili is assembled into a fibrillar tip structure in the Enterobacteriaceae. Proc Natl Acad Sci USA 1995;92:2081-2085. [PubMed: 7892228]

\section{Glossary}

\section{Riboswitch}

An mRNA control element that changes conformation in response to the binding of a metabolite (for example, glycine, lysine and coenzyme $\mathrm{B}_{12}$ ) and influences gene expression.

\section{Microbiota}

The entire collection of microorganisms (bacteria, archaea, fungi, sometimes protozoa and viruses) that are resident on or in the host.

Pilus

A non-flagellar filamentous appendage that is formed on the surface of many bacteria.

\section{Quorum sensing}

(QS). The process by which bacteria use signalling molecules to monitor bacterial density and coordinate gene expression in a population-density-dependent manner.

Adhesin

The surface-exposed bacterial molecule that mediates specific binding to a receptor or ligand on a target cell.

\section{Autotransporter}

A large family of secreted proteins in Gram-negative bacteria that harbour three functional domains - the amino-terminal signal peptide, the secreted mature protein (passenger domain) and a carboxy-terminal translocator domain - to allow secretion of the passenger protein.

Biofilm

A community of cells that are attached to a surface or interface or to each other, and are imbedded in a self-made, protective matrix of extracellular polymeric substances.

\section{Chaperone-usher system}


A system that facilitates the folding, transport and ordered assembly of pilus subunits at the cell surface.

Botulism

A rare, but serious illness that is caused by a nerve toxin, botulinum, that is produced by the bacterium Clostridium botulinum.

\section{Chemical genetics}

The strategy of using small molecules to alter and interrogate biological processes. The small-molecule tools of dissection in this approach harbour the precious chemical scaffolds that may lead directly to new therapeutics.

\section{Project BioShield}

The Project BioShield Act was incorporated into law by the United States government in July 2004. Through Project BioShield, $\$ 5.6$ billion will be invested by 2013 in the development of new technological and therapeutic countermeasures against potential bioterrorism agents and to purchase and stockpile effective therapeutics to prevent and treat the illnesses that are related to these threats.

\section{Haemolytic uraemic syndrome}

A disease that primarily affects infants and children and is characterized by the loss and destruction of red blood cells. Occurs most commonly in children after a gastrointestinal infection or upper respiratory-tract infection and can lead to kidney failure. 


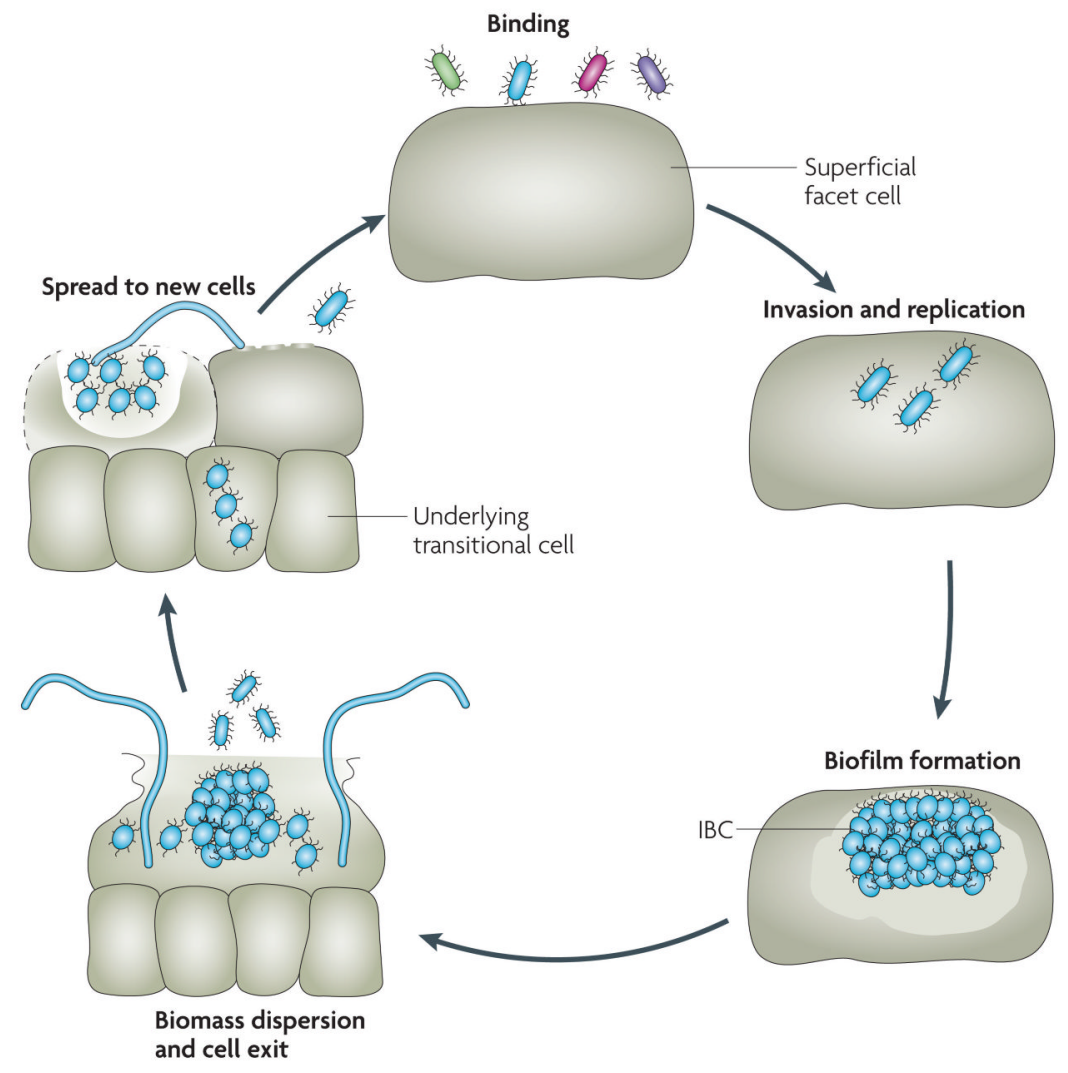

Figure 1. Multi-step pathogenic cascade of uropathogenic Escherichia coli (UPEC)

UPEC coordinate highly organized temporal and spatial events to colonize the urinary tract. UPEC bind to and invade the superficial facet cells that line the bladder lumen, where they rapidly replicate to form a biofilm-like intracellular bacterial community (IBC). In the IBC, bacteria find safe haven, are resistant to antibiotics and subvert clearance by host innate immune responses. UPEC can persist for months in a quiescent bladder reservoir following acute infection and challenge current antimicrobial therapies. Quiescent bacteria can re-emerge from their protected intracellular niche and be a source of recurrent urinary-tract infections. Insight into the processes that accompany IBC formation and biofilm dispersal, as well as the factors that drive bacteria into the reservoir, may aid the design of preventive or therapeutic strategies for recurrent infections. 
a

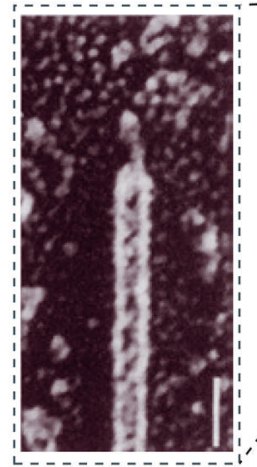

Type 1 pilus

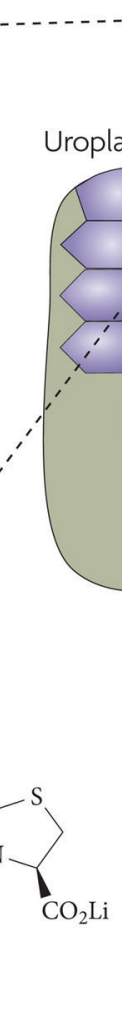

Pilicide

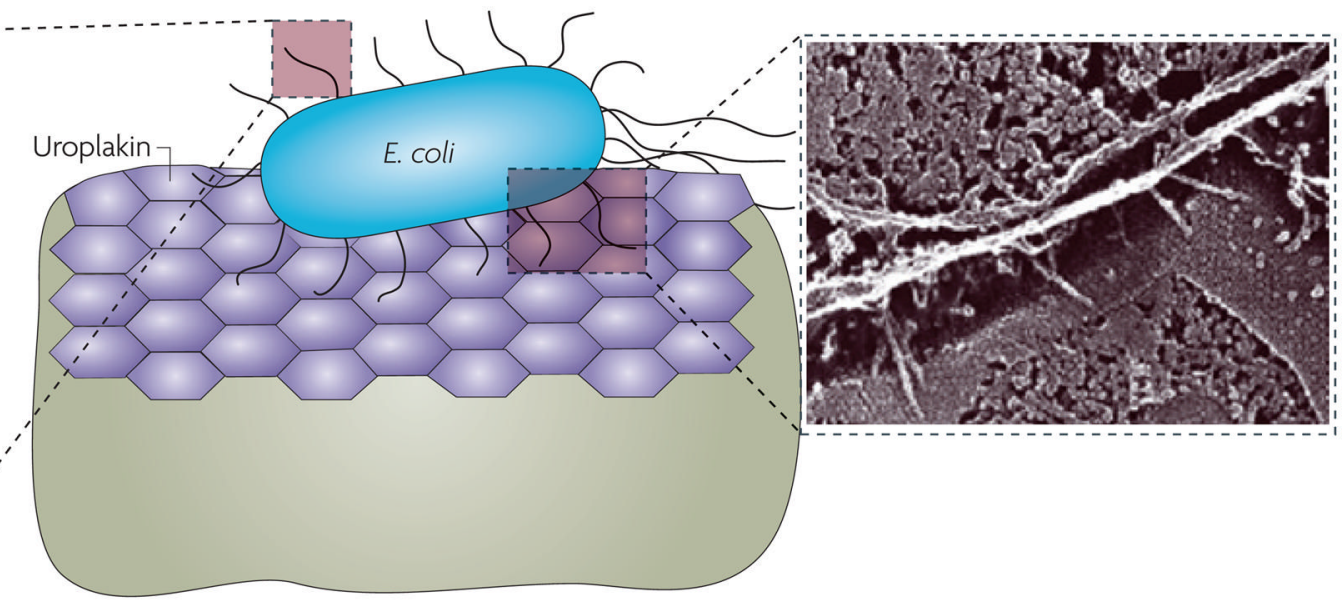

b

Superficial facet cell<smiles>CC(C)c1c(Cc2cccc3ccccc23)c(CN2CCOCC2)c(=O)n2c1SC[C@H]2C(=O)O</smiles>

No compound

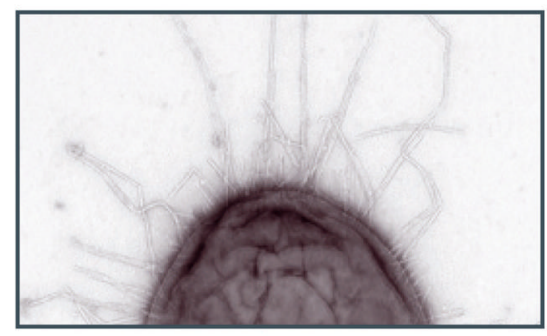

Plus pilicide

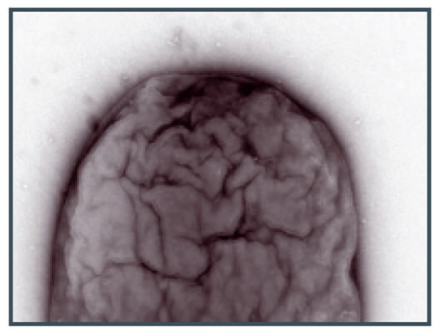

Figure 2. Targeting microbial adhesion

a Pathogenic Escherichia coli use type 1 pili to bind to hexameric uroplakin protein arrays on the surface of superficial facet cells that line the bladder lumen. Type 1 pili mediate the binding to, and subsequent invasion of, these cells. $\mathbf{b} \mid$ Pyridone-based pilicides inhibit pilus biogenesis by disrupting chaperone-usher protein interactions and dramatically reduce piliation levels. Image on the left in panel a reproduced, with permission, from REF. 102 ○ (1995) National Academy of Sciences. Image on the right in panel a reproduced, with permission, from REF. 35 () (1998) American Association for the Advancement of Science. Images in panel b reproduced, with permission, from REF. 45 @ (2006) National Academy of Sciences. 


\section{a Toxin transcription}

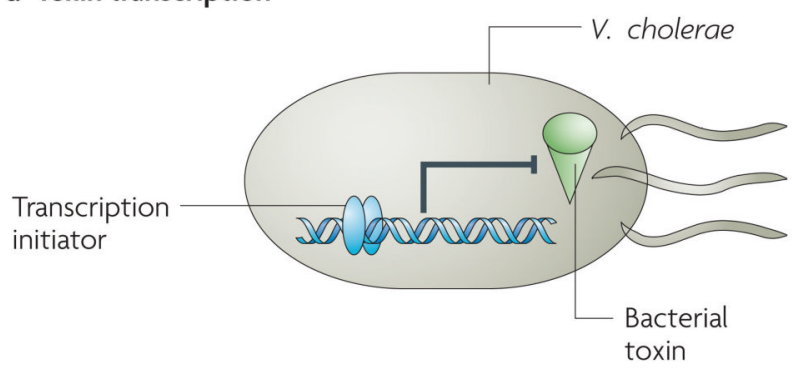

b Toxin trafficking and function
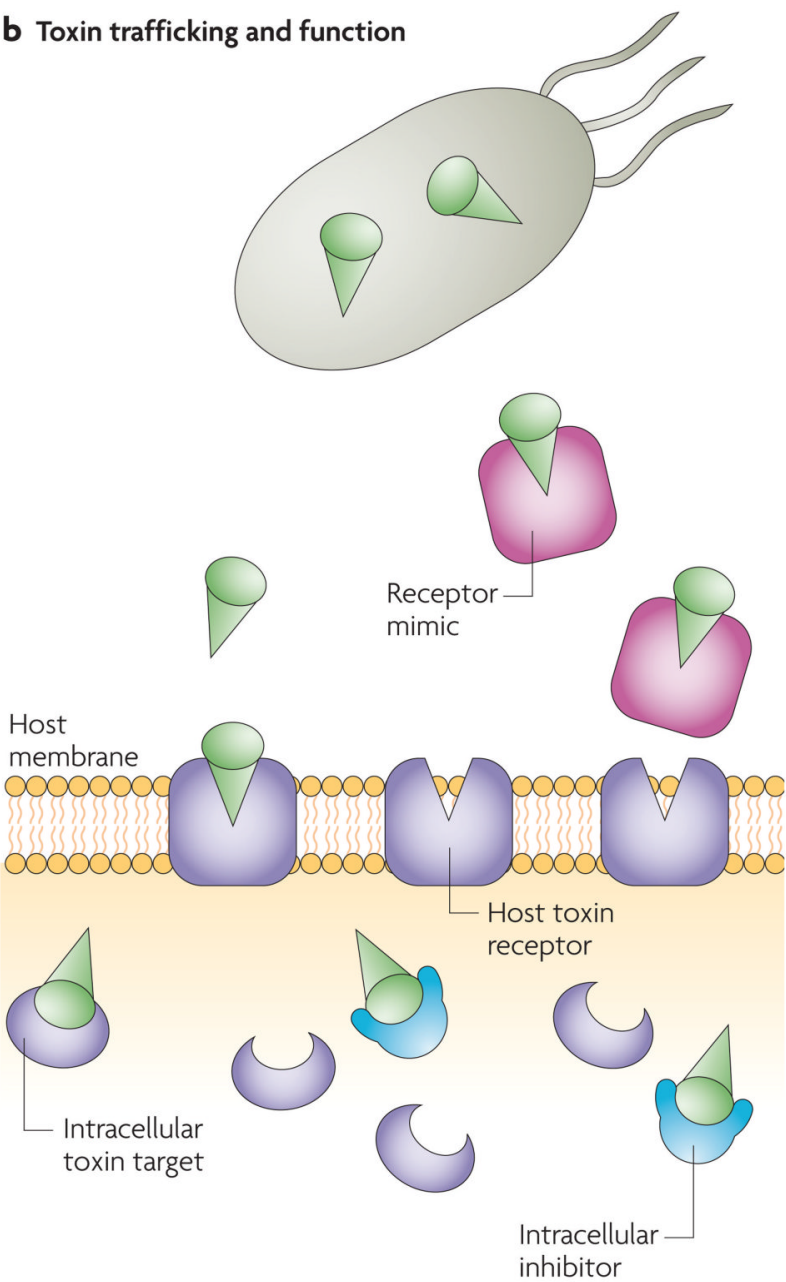

Figure 3. Targeting toxin-powered pathogens

a The inhibition of toxin transcription, as described for Vibrio cholerae, is one way to inhibit the consequences of toxin-mediated virulence. $\mathbf{b} \mid$ Neutralizing toxins, or preventing their trafficking and/or enzymatic activity, at cellular targets is an alternative strategy to inhibit toxin damage to the host. 


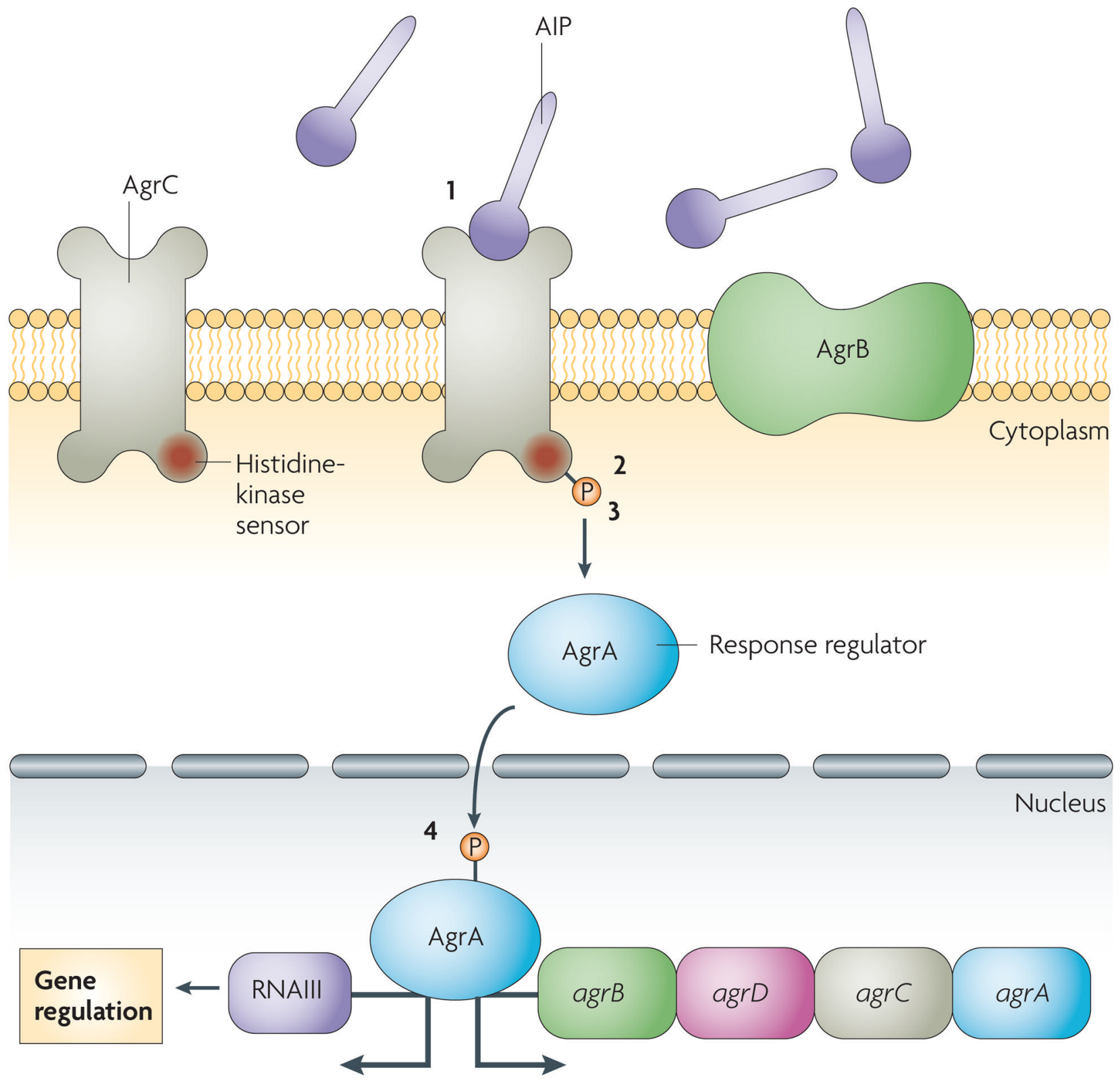

Figure 4. Pairing quorum sensing and two-component signaling in the staphylococcal agr system Staphylococcus aureus uses a two-component response system (TCRS) to mediate quorum sensing (QS). The regulation of QS involves the production of an autoinducer and an increase in its concentration, expression of RNAIII and the subsequent regulation of QS genes. $S$. aureus produces an autoinducing peptide (AIP) that accumulates extracellularly and activates the TCRS. The TCRS involves signal recognition by a histidine kinase (AgrC) (1), followed by histidine phosphorylation (2) and phosphotransfer to a response regulator (AgrA) (3), which then binds to the RNAIII transcript that encodes a small RNA that functions to modulate gene expression of $S$. aureus genes (4). 
Table 1

Representative adhesive fibres, fibre classification and disease association

\begin{tabular}{|c|c|c|c|c|}
\hline \multirow{2}{*}{\multicolumn{5}{|c|}{$\begin{array}{l}\text { Adhesive fibre Assembly proteins } \\
\text { Fibres that use the chaperone-usher pathway }\end{array}$}} \\
\hline & & & & \\
\hline Type 1 pili & FimC and FimD & FimH & $\begin{array}{l}\text { Escherichia coli, } \\
\text { Klebsiella } \\
\text { pneumoniae and } \\
\text { Salmonella species }\end{array}$ & Cystitis \\
\hline P pili & PapD and PapC & PapG & E. coli & Cystitis and pyelonephritis \\
\hline Prs pili & PrsD and PrsC & PrsG & E. coli & Cystitis \\
\hline S pili & SfaE and $\mathrm{SfaF}$ & SfaS & E. coli & $\begin{array}{l}\text { Urinary-tract infection and } \\
\text { newborn meningitis }\end{array}$ \\
\hline Hif pili & HifB and HifC & HifE & $\begin{array}{l}\text { Haemophilus } \\
\text { influenzae }\end{array}$ & Otitis media and meningitis \\
\hline Type 2 and 3 pili & FimB and FimC & FimD & Bordetella pertussis & Whooping cough \\
\hline Pef pili & PefD and PefC & Unknown & $\begin{array}{l}\text { Salmonella } \\
\text { enterica serovar } \\
\text { Typhimurium ( } S \text {. } \\
\text { typhimurium) }\end{array}$ & Gastroenteritis \\
\hline Long polar fimbriae & LpfB and LpfC & Unknown & S. typhimurium & Gastroenteritis \\
\hline MR/K(type 3) pili & MrkB and MrkC & MrkD & K. pneumoniae & Pneumonia \\
\hline Myf fimbriae & MyfB and MyfC & Unknown & $\begin{array}{l}\text { Yersinia } \\
\text { enterocolitica }\end{array}$ & Enterocolitis \\
\hline \multicolumn{5}{|c|}{ Alternate chaperone pathway } \\
\hline CS1 pili & CooB and $\mathrm{CooC}$ & CooD & E. coli & Diarrhoea \\
\hline \multicolumn{5}{|c|}{ Extracellular nucleation-precipitation pathway } \\
\hline Curli & $\begin{array}{l}\text { CsgB (nucleator), CsgE and } \\
\text { CsgF (assembly) and CsgG } \\
\text { (secretion) }\end{array}$ & CsgA (major subunit) & E. coli & Sepsis \\
\hline Tafi & AgfB (nucleator) & AgfA (major subunit) & $\begin{array}{l}\text { Salmonella } \\
\text { enterica serovar } \\
\text { Enteritidis }\end{array}$ & Mouse typhoid \\
\hline \multicolumn{5}{|c|}{ General secretion pathway } \\
\hline \multirow[t]{2}{*}{ Type 4 pili } & \multirow[t]{2}{*}{ General secretion apparatus } & PilC & $\begin{array}{l}\text { Neisseria } \\
\text { gonorrhoea }\end{array}$ & Gonorrhoea \\
\hline & & Pilin protein & $\begin{array}{l}\text { Pseudomonas } \\
\text { aeruginosa, Vibrio } \\
\text { cholerae, } \\
\text { Mycobacterium } \\
\text { bovis and } \\
\text { Dichelobacter } \\
\text { nodosis }\end{array}$ & Cholera \\
\hline \multicolumn{5}{|l|}{ Gram-positive pili } \\
\hline Pili & $\begin{array}{l}\text { LPXTG-motif-mediated } \\
\text { export and covalent } \\
\text { polymerization }\end{array}$ & Unknown & $\begin{array}{l}\text { Corynebacterium } \\
\text { diphtheriae, } \\
\text { Streptococcus } \\
\text { mutans and } \\
\text { Streptococcus } \\
\text { pneumoniae }\end{array}$ & Pneumoccocal diseases \\
\hline
\end{tabular}

Tafi, thin aggregative fimbriae. 
Table 2

Selected two-component response systems (TCRSs) involved in virulence

Histidine-kinase sensor and

response regulator

AgrC; AgrA

$\mathrm{A} \lg \mathrm{D} ; \mathrm{A} \operatorname{lgR}$

RcsC; RcsB

BvgS; BvgA

PhoQ; PhoP

TCRSs involved in the regulation of resistance

TCRSs involved in the regulation of resistance to antibiotics

VanS; VanR

RprX; RprY

\section{Organisms}

Staphylococcus aureus and Staphylococcus epidermidis

Pseudomonas aeruginosa

Escherichia coli

Bordetella pertussis

P. aeruginosa, Salmonella enterica serovar

Typhimurium, Yersinia pestis and Vibrio

Enterococcus faecalis

Streptococcus pneumoniae

Bacteroides fragilis
Associated virulence property

Control of most aggressive virulence factors

Alginate

Capsule

Toxins, adhesins and colonization factors

Divalent cation sensing, modification of lipopolysaccharide and resistance to antimicrobial peptides

Vancomycin resistance

Vancomycin resistance

Tetracycline resistance 